\title{
Simulation of Remdesivir Disposition and Its Drug Interactions
}

\author{
Subrata Deb, Anthony Allen Reeves \\ Department of Pharmaceutical Sciences, College of Pharmacy, Larkin University, Miami, FL, USA
}

Corresponding Author: Subrata Deb, B.Pharm, PhD, Department of Pharmaceutical Sciences, College of Pharmacy, Larkin University; Miami, FL 33169, USA; TEL: 224-310-7870; email: sdeb@alumni.ubc.ca

Received, April 29, 2021; Revised, May 28, 2021; Accepted May 31, 2021, Published, June 5, 2021

\begin{abstract}
Purpose: Remdesivir, a drug originally developed against Ebola virus, is currently recommended for patients hospitalized with coronavirus disease of 2019 (COVID-19). In spite of United States Food and Drug Administration's recent assent of remdesivir as the only approved agent for COVID-19, there is limited information available about the physicochemical, metabolism, transport, pharmacokinetic (PK), and drug-drug interaction (DDI) properties of this drug. The objective of this in silico simulation work was to simulate the biopharmaceutical and DDI behavior of remdesivir and characterize remdesivir PK properties in special populations which are highly affected by COVID-19. Methods: The Spatial Data File format structures of remdesivir prodrug (GS-5734) and nucleoside core (GS-441524) were obtained from the PubChem database to upload into the GastroPlus software 9.8 version (Simulations Plus Inc., USA). The Absorption, Distribution, Metabolism, Excretion and Toxicity (ADMET) Predictor and PKPlus modules of GastroPlus were used to simulate physicochemical and PK properties, respectively, in healthy and predisposed patients. Physiologically based pharmacokinetic (PBPK) modeling of GastroPlus was used to simulate different patient populations based on age, weight, liver function, and renal function status. Subsequently, these data were used in the Drug-Drug Interaction module to simulate drug interaction potential of remdesivir with other COVID-19 drug regimens and with agents used for comorbidities. Results: Remdesivir nucleoside core (GS-441524) is more hydrophilic than the inactive prodrug (GS-5734) with nucleoside core demonstrating better water solubility. GS-5734, but not GS-441524, is predicted to be metabolized by CYP3A4. Remdesivir is bioavailable and its clearance is achieved through hepatic and renal routes. Differential effects of renal function, liver function, weight, or age were observed on the PK profile of remdesivir. DDI simulation study of remdesivir with perpetrator drugs for comorbidities indicate that carbamazepine, phenytoin, amiodarone, voriconazole, diltiazem, and verapamil have the potential for strong interactions with victim remdesivir, whereas agents used for COVID-19 treatment such as chloroquine and ritonavir can cause weak and strong interactions, respectively, with remdesivir. Conclusions: GS-5734 (inactive prodrug) appears to be a superior remdesivir derivative due to its hepatic stability, optimum hydrophilic/lipophilic balance, and disposition properties. Remdesivir disposition can potentially be affected by different physiological and pathological conditions, and by drug interactions from COVID-19 drug regimens and agents used for comorbidities.
\end{abstract}

\section{INTRODUCTION}

Due to its emergent nature, there are limited treatment options available against the coronavirus disease of 2019 (COVID-19). Treatment regimens against COVID-19 focus on preventing replication of the virus as well as managing inflammation and other symptoms (1). Chloroquine, hydroxychloroquine, azithromycin, ivermectin, and lopinavir/ritonavir have been used as treatment options against COVID19 (2). It has been hypothesized that chloroquine and hydroxychloroquine can prevent the viral entry of COVID-19 through angiotensin converting enzyme 2 (ACE2) receptors (3). Ivermectin, which is originally used for parasitic worm infections, antiviral activity is postulated to be due to its ability to inhibit import of viral proteins and inhibit the attachment of viruses through modulation of transmembrane receptor CD147 (4). Lopinavir and ritonavir is a combination, which was originally approved to treat human immunodeficiency virus, is used against severe acute respiratory syndrome coronavirus 2 (SARS-CoV-2) through inhibition of $3 \mathrm{CL}^{\text {pro }}$, its main protease enzyme (5). None of these treatment options have shown to be significantly beneficial in treating COVID-19. However, dexamethasone and remdesivir have shown to be somewhat effective in treating COVID-19 $(2,6)$. In United States, remdesivir is the only Food and Drug 
Administration (FDA)-approved drug for the treatment of COVID-19 (7).

Remdesivir is a nucleoside analog that was originally developed against Ebola (8). It is a prodrug that needs to be activated by esterase and through a series of phosphorylations to its active form. Specifically, remdesivir is an adenosine analog prodrug (GS-5734) which is metabolically activated to GS-441524 (9). GS-441524 is then uptaken by infected SARS-CoV-2 cells where it becomes GS443902, a nucleoside triphosphate metabolite, after a series of phosphorylations (9). The active nucleoside triphosphate metabolite selectively inhibits viral RNA-dependent RNA polymerase of SARS-CoV-2 and thus prevents its replication (9). In clinical trials, remdesivir shortened the recovery time of hospitalized COVID-19 patients when compared to placebo (10). It was approved by United States FDA in October 2020 for the treatment of COVID-19 patients receiving supplemental oxygen with a total duration of therapy of at least five days $(7,9)$. In patients who do not improve within five days or require mechanical ventilation a therapy duration of ten days is recommended (9). In adult patients, the recommended regimen is a load dose of $200 \mathrm{mg}$ on day 1 , followed by $100 \mathrm{mg}$ once daily (9). In pediatric patients, $<12$ years old or those who weigh 3.5 to $<40 \mathrm{~kg}$ the recommended regimen is a load dose of $5 \mathrm{mg} / \mathrm{kg} / \mathrm{dose}$ on day 1 , followed by 2.5 $\mathrm{mg} / \mathrm{kg} /$ dose once daily (11). In pediatric patients, who weighs $\geq 40 \mathrm{~kg}$ the dose regimen is the same as adults (11). Although remdesivir was approved by the FDA, it lacks extensive pharmacokinetics (PK) and drug interaction studies.

Biopharmaceutical and PK properties of the small molecules facilitate the entry, action, and elimination of the drugs. Physicochemical properties (e.g., partition coefficient, acid dissociation constant) are important drug-like characteristics that determine the ability of the molecule to reach to the systemic circulation and perform the pharmacological actions (12). Identification of cytochrome P450 (CYP)mediated metabolism and transporter profile allows to predict the drug interaction potential (13). Similarly, pharmacokinetic properties define the ability of a drug to reach to the site of action and potential to cause dose-related toxicity. Most importantly, understanding the interactions involving metabolic enzymes are critical in the therapeutic outcome of the drugs. In silico or computer-based simulation software such as GastroPlus (Simulations Plus Inc., USA) can be used to enhance and aid drug characterization when extensive preclinical and clinical data are limited. GastroPlus has the ability to predict physicochemical, PK, and potential drug-drug interaction (DDI) properties based on the structural features and dose regimen (14). The physicochemical and metabolic/transporter profiles are derived from the Absorption, Distribution, Metabolism, Excretion, and Toxicity (ADMET) Predictor module, whereas physiologically based pharmacokinetic (PBPK)-based PKPlus module is used for PK simulations, and finally, Drug-Drug Interaction module is used to predict drug interaction potential through GastroPlus software (15). DDI simulations in GastroPlus predict the ability of a pair of drugs to affect the metabolism and disposition of each other. The analyses of "victim" (its metabolism is either inhibited or induced by other chemicals) and "perpetrator" (causes inhibition or induction of metabolic enzyme of other drugs) perspective allow to calibrate the dosing regimen.

Remdesivir has shown promises to be effective against SARS-CoV-2 $(9,16)$. However, there is limited information available about its ADME and PK properties (17-19). In addition, DDIs related to COVID-19 regimens and comorbidities remain totally unevaluated. The ADME and PK properties of remdesivir were predicted using in silico GastroPlus software. The PBPK models of healthy adults as well as for patients with obesity and liver/renal dysfunction were built. The DDI analyses were carried out with remdesivir and the drugs for standard COVID-19 supportive care, inpatient and comorbidities associated with COVID-19 (e.g., cardiovascular agents). The objective of this study was to provide in silico prediction on ADME, PK, and potential DDIs involving remdesivir, and characterize remdesivir PK properties in special populations which are highly affected by COVID-19.

\section{MATERIALS AND METHODS}

\section{Uploaded Remdesivir and DDI Simulation Structures}

The Spatial Data File (SDF) format of the chemical structures were used to carry out the simulation experiments. SDF files were obtained from PubChem, a National Institutes of Health chemical structure database (20). GS-5734 (the inactive prodrug) and GS-441524 (the nucleoside core) remdesivir structures were used in the in silico analysis (Figure 1). The drugs uploaded for DDI simulation were chloroquine, dexamethasone, ritonavir, lopinavir, azithromycin, ivermectin, 

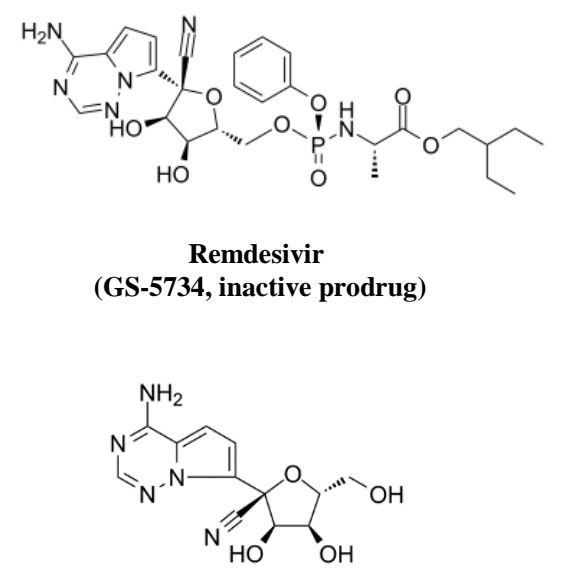

Nucleoside Core

(GS-441524)

Figure 1. Remdesivir prodrug and nucleoside core structures (20).

carbamazepine, phenytoin, amiodarone, voriconazole, diltiazem, verapamil, cyclosporine, and nicardipine. All drug dosages were verified for their dose and route of administration from their respective FDA package inserts.

\section{GastroPlus}

GastroPlus software 9.8 version (Simulations Plus Inc., Lancaster, CA, USA) is an in silico simulation software that can predict ADME, pharmacokinetic, and metabolic interaction properties of drugs in different species including in humans and rodents. The foundational model utilizes several aspects of GastroPlus functionalities such as ADMET Predictor, Metabolism and Transporter, and PKPlus. Since ADME and PK significantly differ based on route of administration, this software allows to choose from all the major dosage forms such as oral, intravenous, and inhalation. The simulation process was initiated by navigating through different Tabs, namely, Compound, Gut Physiology, Pharmacokinetics, Simulation, and Graph. Among these, except Gut Physiology, rest of the features are compound dependent. Gut physiology features (e.g., $\mathrm{pH}$, volume, gastrointestinal length, metabolic enzyme expression) are set for healthy individuals with average population physiological specifications in fasted conditions. Each SDF structure was imported into Compound Tab to create a "New Drug Database". Subsequently, these GastroPlus drug databases were used for the ADMET Predictor, PKPlus, and Drug-Drug Interaction (DDI) modules.
The quantitative and visual outputs of pharmacokinetic properties were obtained from the Simulation and Graph Tabs. The PBPK models for different conditions (e.g., obesity, hepatic disorders, renal disorders) were developed to carry out pharmacokinetic simulations. The DDI module was used to simulate the potential interactions of remdesivir with other COVID-19 related drugs and agents for preexisting conditions.

\section{Simulation of ADME Properties}

The ADMET Predictor functionality in GastroPlus software was used to estimate $\log \mathrm{P}$, molecular weight, solubility, human jejunum effective permeability (Peff), diffusion coefficient, pKa, CYPmediated metabolism and transport, and effective blood brain barrier permeability. The "New Drug Database" developed with the SDF structure was imported using "Import Structure Properties". The "Use Predicted" feature was opted to activate ADMET Predictor analyses. The software can predict metabolism mediated by CYP1A2, CYP2A6, CYP2B6, CYP2C8, CYP2C9, CYP2C19, CYP2D6, CYP2E1, and CYP3A4. The structural features of the compound facilitate the prediction of CYP isoforms and fraction metabolized (fm). It can also produce a qualitative measure of involvement of transporters such as organic anion transporter (OAT), P-glycoprotein (P-gp), and breast cancer resistance protein (BCRP). The extended clearance classification system (ECCS) classification can predict the extent and level of metabolism and renal output of a drug denoting it as major (extensive output) or minor (minimal output).

\section{Pharmacokinetic Simulation of Remdesivir}

The pharmacokinetic properties of remdesivir prodrug (GS-5734) and nucleoside core (GS441524) were simulated with $200 \mathrm{mg}$ or $100 \mathrm{mg}$ dose given intravenously over 24 hours. The physicochemical properties and ADME properties derived in the previous step were used in the Pharmacokinetic Tab to predict drug disposition profile. The drug disposition-based parameters were simulated in a compartmental PK model in a virtual patient with healthy physiological conditions. The PBPK model utilized in this simulation included different tissues as compartments that are connected by the arterial/venous blood movement. The virtual individual included in this simulation was considered to be from American population, 30-year-old healthy male, $86.27 \mathrm{~kg}$ weight, $176.14 \mathrm{~cm}$ height, and $24.6 \%$ body fat. The $\mathrm{pH}$, length and volumes of GI segments 
were per the fasted condition in a healthy human. Characteristics of different populations used in the simulation study are summarized in Supplemental Table S1. The simulation duration was 24 hours and estimated maximum (or peak) plasma concentration $\left(\mathrm{C}_{\max } \mu \mathrm{g} / \mathrm{mL}\right)$, maximum concentration in liver $\left(\mathrm{C}_{\text {maxLiver }} \mu \mathrm{g} / \mathrm{mL}\right)$, time required to maximum plasma concentration $\left(\mathrm{T}_{\max } \mathrm{h}\right)$, area under the curve from 0 to infinity $\left(\mathrm{AUC}_{0-\infty}\right)$, half-life $\left(\mathrm{T}_{1 / 2}\right)$, and systemic clearance (CLsys).

\section{PBPK Modeling of Remdesivir}

PBPK modeling of GastroPlus were used to simulate different patient populations based on age, weight, health status, and disease severity. The PBPK models were developed using ages 10, 12, 18, 30, 50, and 75 years. Different weights based on a body mass index (BMI) scale of normal (BMI 18.5-24.9), overweight (BMI 25-29.9), and obese (BMI $\geq 30$ ) were included in the Pharmacokinetic Tab of GastroPlus software (21). The health status and disease severity modelled were healthy, renal impairment, and hepatic impairment. Healthy was defined as not having any renal or hepatic impairment or weight issues. Renal impairment was defined based on estimated glomerular filtration rate (eGFR) and age of the modelled patient (14). Based on the typical clinical presentations, we assessed patients with healthy $\left(\mathrm{eGFR}=90 \mathrm{~mL} / \mathrm{min} / 1.73 \mathrm{~m}^{2}\right)$, moderate $(\mathrm{eGFR}=59$ $\left.\mathrm{mL} / \mathrm{min} / 1.73 \mathrm{~m}^{2}\right)$, and severe $\quad(\mathrm{eGFR}=29$ $\mathrm{mL} / \mathrm{min} / 1.73 \mathrm{~m}^{2}$ ) renal function (14). Liver impairment was classified as per the Child-Pugh scale of grade A, B, or C (22). We assessed healthy patients who were given a defined Child-Pugh score of 0 . Grade A was considered mild liver impairment defined as a Child-Pugh score of 5. Grade B was considered moderate liver impairment defined as a Child-Pugh score of 7 . Grade $\mathrm{C}$ was considered severe liver impairment defined as a Child-Pugh score of 10 (22).

\section{Correlation Study with Microsoft Excel}

Microsoft excel was used to carry out correlation analysis. The physiological status (age, obese, liver/renal impairment) was plotted against pharmacokinetic parameters of maximum plasma concentration $\left(\mathrm{C}_{\max }\right)$, maximum concentration in the liver $\left(\mathrm{C}_{\text {maxLiver }}\right)$, area under the curve to infinite time $\left(\mathrm{AUC}_{0-\infty}\right)$, systemic clearance (CLsys), steady state volume of distribution (Vss), and half-life $\left(\mathrm{T}_{1 / 2}\right)$. The association was derived from a liner regression from scatter plots. Correlation was interpreted by $\mathrm{R}^{2}$ and classified as either weak, moderate, fairly strong, or strong. An alpha significance level of 0.05 was set. A $p$ value of $<0.05$ was considered statistically significant.

\section{Drug-Drug Interaction Simulation with Remdesivir}

The metabolic interactions involving remdesivir were simulated using Drug-Drug Interaction module of GastroPlus in steady-state mode. The physicochemical, ADME, and pharmacokinetic parameters obtained in the previous steps were used as input in the DDI simulation study. In different combinations, remdesivir was considered as "victim" and the co-administered medications were treated as "perpetrator" in the metabolic interaction Tabs. Potential interactions of remdesivir that were assessed include COVID-19 regimens (chloroquine, hydroxychloroquine, azithromycin, ivermectin, and lopinavir/ritonavir), supportive care medications commonly used in the intensive care unit (ICU) and inpatient hospitals (carbamazepine, phenytoin, amiodarone/desethylamiodarone, voriconazole), and comorbidity medications associated with COVID-19 (diltiazem, verapamil, cyclosporine, and nicardipine). The inhibition enzyme kinetics constants $\left(\mathrm{Ki}, \mathrm{IC}_{50}\right)$ and induction kinetics constant $\left(\mathrm{EC}_{50}\right)$ of each "perpetrator" medications were obtained from literature (23-36). Doses for each perpetrator medication were obtained from the FDA approved package inserts. The DDI simulations for remdesivir $(200 \mathrm{mg})$ and various medications were conducted using steady-state DDI simulation in GastroPlus over a period of 24 hours. The PBPK model of a 30 -year-old weighing $85.53 \mathrm{~kg}$, with BMI of 27.488, and classified as healthy was used for the simulated DDI environment. To classify each DDI, GastroPlus simulated monitoring of AUC ratio in the presence and absence of the perpetrator was utilized. These potential interaction categories of no interaction, weak, moderate, strong were based on the FDA draft guidance for drug interaction studies (37). Weak inhibitors were defined as having a predicted AUC ratio in the range 1.25 to 2 . Moderate inhibitor AUC ratios can be in the range of 2 to 5 . Strong inhibitors were defined as having an AUC > 5. Inducers were defined by the change in baseline and predicted AUC. Weak inducers were defined as predicted AUC ratio in the range of 0.5 to 0.8 and a less than two-fold difference from the baseline. Moderate inducers were specified as predicted AUC ratio in the range 0.2 to 0.5 and a two- to five-fold difference from the baseline. Strong inducers were 
defined as having a predicted AUC ratio of $<0.2$ and more than five-fold difference from the baseline.

\section{RESULTS}

\section{Physicochemical Properties of Remdesivir}

The simulated relevant physicochemical properties of remdesivir are shown in Table 1. The molecular weights of GS-5734 (inactive prodrug) and GS441524 (nucleoside core) were $602.59 \mathrm{~g} / \mathrm{mol}$ and $291.27 \mathrm{~g} / \mathrm{mol}$, respectively. The predicted lipophilicity and aqueous solubility properties differed between parent remdesivir and nucleoside core. GS-5734 had a $\log$ P (octanol-water partition coefficient) of 1.6 and solubility of $0.0228 \mu \mathrm{g} / \mathrm{mL}$, whereas the $\log$ P and solubility of GS-441524 were -1.09 and of $2.6 \mu \mathrm{g} / \mathrm{m}$, respectively. This indicates that GS-441524 is more hydrophilic than GS-5734. The diffusion coefficient for GS-5734 was 0.51 $\mathrm{cm}^{2} / \mathrm{s} \times 10^{-5}$ and for GS- 441524 was $0.84 \mathrm{~cm}^{2} / \mathrm{s} \mathrm{x} 10^{-}$ ${ }^{5}$ which suggest differential diffusivity. The predicted human jejunum effective permeability (Peff) of the remdesivir derivatives (GS-5734 and GS-441524) were $0.0841 \mathrm{~cm} / \mathrm{s} \mathrm{x} 10^{-4}$ and $0.3 \mathrm{~cm} / \mathrm{s} \mathrm{x} 10^{-4}$, respectively. The lower lipophilicity and higher aqueous solubility profiles of GS-441524 are consistent with its comparatively higher diffusion coefficient and permeability features than GS-5734. The MedChem Designer module calculated the pKa microstates. Microstates occur due to different protonation states of a chemical structure (38). GS$5734 \mathrm{pKa}$ microstates were 10.93 (acid) and -2.22 (base). In comparison, GS-441524 had only one pKa microstate of 3.76 (base).

Table 1. Predicted physicochemical and ADME properties of remdesivir and its nucleoside core.

\begin{tabular}{lll}
\hline & GS-5734, inactive prodrug & GS-441524, nucleoside core \\
\hline $\log$ P & 1.6 & -1.09 \\
$\mathbf{M W}(\mathbf{g} / \mathbf{m o l})$ & 602.59 & 291.27 \\
Solubility $(\boldsymbol{\mu g} / \mathbf{m L})$ & 0.0228 & 2.6 \\
Diff. Coeff $\left(\mathbf{c m}^{2} / \mathbf{s} \mathbf{x} \mathbf{1 0}^{-5}\right)$ & 0.51 & 0.84 \\
$\mathbf{P}_{\text {eff }}\left(\mathbf{c m} / \mathbf{s} \times \mathbf{1 0}^{-4}\right)$ & 0.0841 & 0.3 \\
$\mathbf{p K a}$ Microstates & Acid (10.93); Base (-2.24) & Base (3.76) \\
BBB Penetration & High (68\%) & High (82\%) \\
Predicted CYP fm & CYP3A4 = 100\% & N/A \\
ECCS Classification & Class 4 renal (major) and & Class 4 renal (major) \\
& metabolism (minor) & \\
Transporter involved & OATP1B1, OATP1B3, P-gp, & OATP1B3, OCT1, OAT3, P-gp \\
\hline ECCS, Extended Clearance Classification System; BBB, Blood brain barrier; fm, fraction metabolized. \\
\hline
\end{tabular}

\section{Metabolism and Transport Characteristics of Remdesivir}

The simulated metabolism and transport characteristics of both remdesivir structures are listed in Table 1. GS-5734 has a predicted CYP fraction metabolism (fm) of $100 \%$ with CYP3A4. The ADMET simulation did not identify CYP involvement with GS-441524 metabolism. GS-5734 is predicted to be a substrate for OATP1B1, OATP1B3, P-gp, and BCRP transporters. Similarly, GS-441524 was associated with OATP1B3, OCT1, OAT3, and P-gp transporters The ECCS for GS-5734 has been predicted to be class 4 renal route as the major elimination path and metabolism as the minor pathway with GS-441524 is also denoted as ECCS class 4 category.

\section{Remdesivir PK Attributes}

The simulated pharmacokinetics properties of remdesivir derived compounds were derived with $200 \mathrm{mg}$ IV dose for GS-5734 (Table 2) and for GS441524 (Table 3). In a healthy 30-year-old male GS5734 had a $\mathrm{C}_{\max }$ of $0.156 \mu \mathrm{g} / \mathrm{mL}, \mathrm{C}_{\text {maxLiver }}$ of 0.014 $\mu \mathrm{g} / \mathrm{mL}, \mathrm{AUC}_{0-\infty}$ of $3.658 \mu \mathrm{g}-\mathrm{h} / \mathrm{mL}$, CLsys of 53.363 
$\mathrm{L} / \mathrm{h}, \mathrm{Vss} 31.281 \mathrm{~L}$, and $\mathrm{T}_{1 / 2}$ of $0.406 \mathrm{~h}$. Similarly, the predicted pharmacokinetic values of GS-441524 in a healthy 30-year-old male were $1.54 \mu \mathrm{g} / \mathrm{mL} \mathrm{C} \mathrm{C}_{\max }$, $0.89 \mu \mathrm{g} / \mathrm{mL} \mathrm{C}_{\text {maxLiver, }} 27.873 \mu \mathrm{g}-\mathrm{h} / \mathrm{mL} \quad \mathrm{AUC}_{0-\infty}$, 5.205 L/h CLsys, 34.59 L Vss, and $4.61 \mathrm{~h} \mathrm{~T}_{1 / 2}$. The time taken to achieve maximum plasma concentration $\left(\mathrm{T}_{\max }\right)$ is $24 \mathrm{~h}$. The PK simulation with $100 \mathrm{mg}$ IV dose indicates $\mathrm{C}_{\max }, \mathrm{C}_{\operatorname{maxLiver}}$, and $\mathrm{AUC}_{0-\infty}$ values were about $50 \%$ of the $200 \mathrm{mg}$ IV dose, whereas CLsys, Vss, and $T_{1 / 2}$ remained constant which indicates that these are the intrinsic characteristics of the drug molecule (Supplemental Table S3).

\section{Effect of Different Physiological and Pathological Conditions on Remdesivir PK}

Different PBPK models based on age, obesity, renal, and liver function status were used to understand PK properties in special population (Table 2, Figure 2). There appears to be a U-shape relationship between age and some PK parameters. As age increased $\mathrm{C}_{\text {maxLiver }}$, CLsys, Vss, and $\mathrm{T}_{1 / 2}$ increased as well. On the contrary, as age increased Cmax, and $\mathrm{AUC}_{0-\infty}$ parameters demonstrated a U-shape profile with higher $\mathrm{Cmax}$ and $\mathrm{AUC}_{0-\infty}$ in the pediatric and older subjects than the average adults. In a healthy 12 -yearold male the predicted $\mathrm{C}_{\max }, \mathrm{C}_{\operatorname{maxLiver}}, \mathrm{AUC}_{0-\infty}$, CLsys, Vss, $\mathrm{T}_{1 / 2}$ were $0.217 \mu \mathrm{g} / \mathrm{mL}, 0.013 \mu \mathrm{g} / \mathrm{mL}$, $5.134 \mu \mathrm{g}-\mathrm{h} / \mathrm{mL}, 38.658 \mathrm{~L} / \mathrm{h}, 17.295 \mathrm{~L}$, and $0.313 \mathrm{~h}$, respectively. The predicted $\mathrm{PK}$ parameters for a healthy 30-year-old were $C_{\max }$ of $0.156 \mu \mathrm{g} / \mathrm{mL}$, $\mathrm{C}_{\text {maxLiver }}$ of $0.014 \mu \mathrm{g} / \mathrm{mL}, \mathrm{AUC}_{0-\infty}$ of $3.658 \mu \mathrm{g}-\mathrm{h} / \mathrm{mL}$, CLsys of $53.363 \mathrm{~L} / \mathrm{h}$, Vss of $31.281 \mathrm{~L}$, and $\mathrm{T}_{1 / 2}$ of $0.406 \mathrm{~h}$. In the healthy geriatric population represented by the 75 -year-old $\mathrm{C}_{\max }$ was 0.205 $\mu \mathrm{g} / \mathrm{mL}, \mathrm{C}_{\text {maxLiver }} 0.014 \mu \mathrm{g} / \mathrm{mL}, \mathrm{AUC}_{0-\infty} 4.781 \mu \mathrm{g}$ $\mathrm{h} / \mathrm{mL}$, CLsys $40.558 \mathrm{~L} / \mathrm{h}$, Vss $30.043 \mathrm{~L}, \mathrm{~T}_{1 / 2} 0.513 \mathrm{~h}$. In the obese PBPK model, increase in weight led to lower $\mathrm{C}_{\max }, \mathrm{C}_{\max L i v e r}, \mathrm{AUC}$, and $\mathrm{T}_{1 / 2}$. However, CLsys, and Vss both increased at higher weights. The simulated moderate and severe renal impairment increased CLsys. As the Child-Pugh scale (A, B, and $C$ ) increased the $\mathrm{PK}$ values of $\mathrm{C}_{\max }, \mathrm{C}_{\text {maxLiver }}, \mathrm{AUC}_{0 \text { - }}$ $\infty$, and $\mathrm{T}_{1 / 2}$ decreased. CLsys, and Vss increased with worsened liver impairment. The PBPK model for obesity with severe renal impairment and liver impairment was simulated in a 30 -year-old with a BMI of 31. In an obese subject with severe renal impairment, simulated PK characteristics had Cmax of $0.156 \mu \mathrm{g} / \mathrm{mL}, \mathrm{C}_{\text {maxLiver }}$ of $0.012 \mu \mathrm{g} / \mathrm{mL}, \mathrm{AUC}_{0-\infty}$ of $3.646 \mu \mathrm{g}-\mathrm{h} / \mathrm{mL}$, CLsys of $53.529 \mathrm{~L} / \mathrm{h}$, Vss of 31.673 $\mathrm{L}$, and $\mathrm{T}_{1 / 2}$ of $0.407 \mathrm{~h}$. The PK parameters in the virtual subjects with obesity and Child-Pugh grade C were $\mathrm{C}_{\max }$ of $0.139 \mu \mathrm{g} / \mathrm{mL}, \mathrm{C}_{\operatorname{maxLiver}}$ of $0.009 \mu \mathrm{g} / \mathrm{mL}$, $\mathrm{AUC}_{0-\infty}$ of $3.27 \mu \mathrm{g}-\mathrm{h} / \mathrm{mL}$, CLsys of $59.808 \mathrm{~L} / \mathrm{h}$, Vss of $31.673 \mathrm{~L}$, and $\mathrm{T}_{1 / 2}$ of $0.367 \mathrm{~h}$.

\section{Correlation of Physiological and Pathological Status and Pharmacokinetic Parameters}

The relationship between physiological status (e.g., age, liver function, renal function) with pharmacokinetic parameters are depicted in Figure 2 and Table 4. Age did not have any correlation with $\mathrm{C}_{\max }, \mathrm{AUC}_{0-\infty}$, Vss, and CLsys. However, it demonstrated significant relationship with $\mathrm{C}_{\text {maxLiver }}$ and $\mathrm{T}_{1 / 2}$. Liver status had a fairly strong positive correlation with $\mathrm{C}_{\max }$, CLsys and $\mathrm{T}_{1 / 2}$, whereas it had strong positive correlation with $\mathrm{C}_{\text {maxLiver }}$ and Vss. Finally, renal status had only a fairly strong positive correlation with Vss and a strong positive correlation with $\mathrm{C}_{\max }, \mathrm{C}_{\operatorname{maxLiver}}, \mathrm{AUC}_{0-\infty}, \mathrm{CLsys}$, and $\mathrm{T}_{1 / 2}$. However, except $\mathrm{C}_{\text {maxLiver}}$, other parameters did not show significance with renal function status, potentially due to narrow range of values between different renal functionalities (healthy, moderate, severe) and limited number of clinical classifications for renal functions. Similar narrow range of PK parameter values was also observed for the relationship between $\mathrm{AUC}_{0-\infty}$ and liver function status, which was reflected in the lack of statistical significance for that particular comparison.

\section{DDI Potential of Remdesivir with COVID-19 Regimens and Comorbidity Drugs}

Remdesivir was predicted to be a substrate of CYP3A4. DDI potential of remdesivir with a total of fifteen drugs, which are CYP3A4 inducers and inhibitors, was simulated. DDIs were conducted in steady state mode with the outcomes shown in Table 5 .

The COVID-19 drug regimens simulated with remdesivir were chloroquine, dexamethasone, ritonavir, lopinavir, azithromycin, and ivermectin. Chloroquine is predicted to be a weak inhibitor of remdesivir metabolism with an AUC ratio of 1.331. Dexamethasone appears to have both CYP inhibition and induction properties $(28,31)$. Interestingly, dexamethasone had no significant interaction with remdesivir. Ritonavir was a strong inhibitor with an AUC ratio of 40.04. Lopinavir, azithromycin, and ivermectin are CYP inhibitors but did not have any significant interaction with remdesivir.

The DDI simulations of remdesivir with drugs for comorbidities include carbamazepine, phenytoin, amiodarone, voriconazole, diltiazem, verapamil, cyclosporine, and nicardipine. Carbamazepine and 
phenytoin which are known CYP3A4 inducers indicate strong interaction with remdesivir with AUC ratios of 0.059 and 0.154 , respectively. All the remaining drugs analyzed in this study were CYP3A4 inhibitors. Amiodarone, voriconazole, diltiazem, and verapamil showed strong interaction potential with AUC ratios ranging from 5.814 to
14.46. The highest inhibition of remdesivir metabolism was observed with verapamil with an AUC ratio of 14.46. Cyclosporine and nicardipine both were classified as CYP3A4 inhibitors but did not demonstrate any significant interaction with remdesivir.
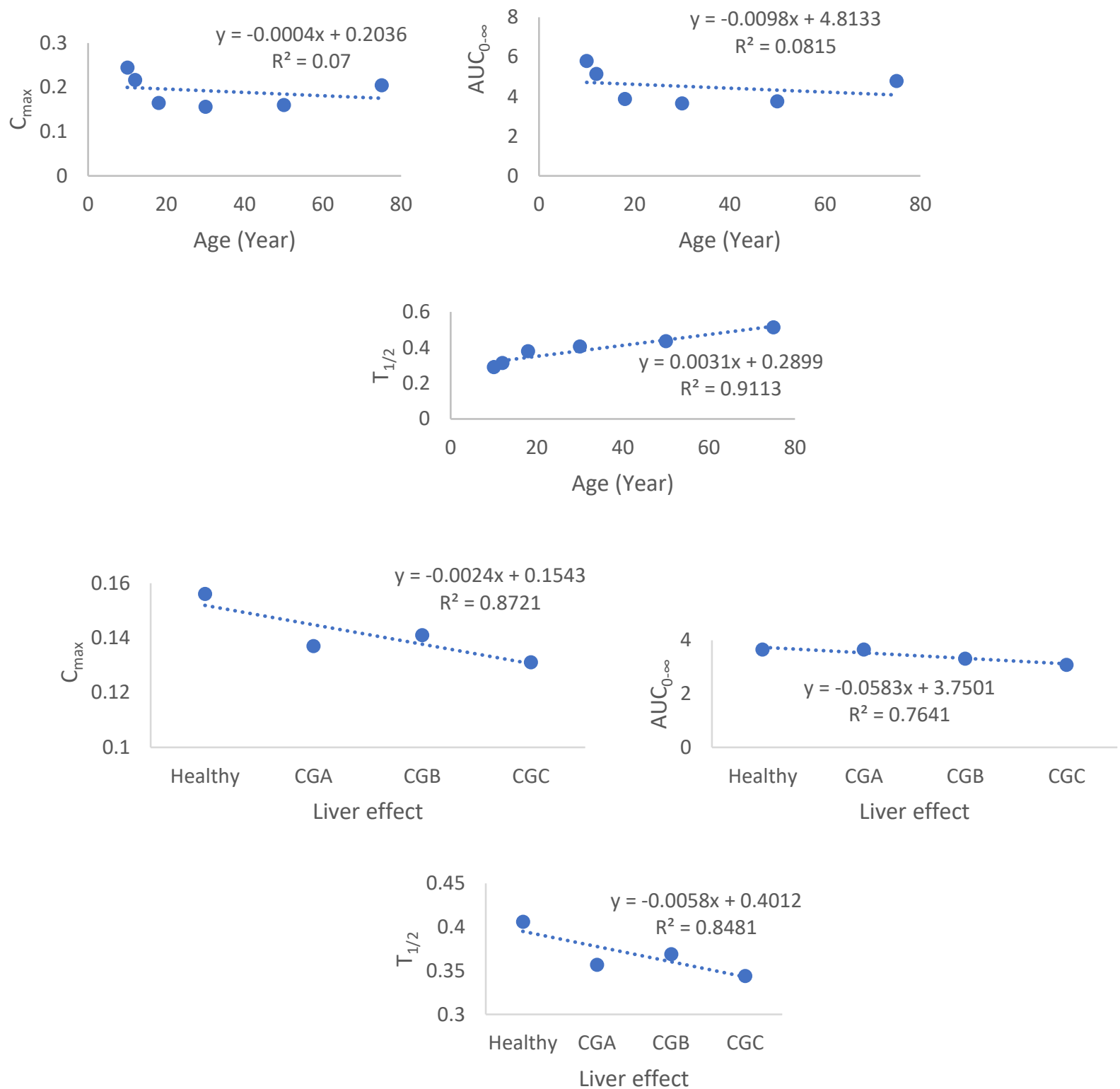

Figure 2. Correlation of physiological status with select simulated pharmacokinetic parameters of remdesivir. eGFR, estimated glomerular filtration rate; CGA, cirrhosis grade A; CGB, cirrhosis grade B; CGC, cirrhosis grade C. Only the correlation between age and $\mathrm{T}_{1 / 2}$ were significant. Other comparisons did not demonstrate significance mainly due to the flatness of a few and the U-shape nature of other relationships. 


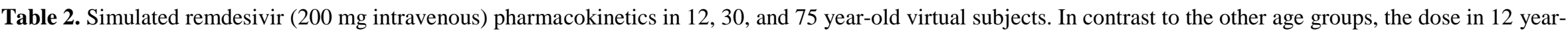
old is calculated based on weight $(5 \mathrm{mg} / \mathrm{kg})$.

\begin{tabular}{|c|c|c|c|c|c|c|c|c|c|c|c|c|c|c|c|c|c|c|}
\hline & \multicolumn{3}{|c|}{$C_{\max }(\mu \mathrm{g} / \mathrm{mL})$} & \multicolumn{3}{|c|}{$C_{\text {maxLiver }}(\mu \mathrm{g} / \mathrm{mL})$} & \multicolumn{3}{|c|}{$\operatorname{AUC}_{0-\infty}(\mu \mathrm{g}-\mathrm{h} / \mathrm{mL})$} & \multicolumn{3}{|c|}{ CLsys (L/h) } & \multicolumn{3}{|c|}{ Vss (L) } & \multicolumn{3}{|c|}{$\mathbf{T}_{1 / 2}(\mathrm{~h})$} \\
\hline & 12 & 30 & 75 & 12 & 30 & 75 & 12 & 30 & 75 & 12 & 30 & 75 & 12 & 30 & 75 & 12 & 30 & 75 \\
\hline Healthy & 0.217 & 0.156 & 0.205 & 0.013 & 0.014 & 0.014 & 5.134 & 3.658 & 4.781 & 38.232 & 53.363 & 40.558 & 17.295 & 31.281 & 30.043 & 0.313 & 0.406 & 0.513 \\
\hline MRI & 0.216 & 0.154 & 0.203 & 0.012 & 0.013 & 0.013 & 5.086 & 3.598 & 4.715 & 38.604 & 54.273 & 41.144 & 17.290 & 31.271 & 30.036 & 0.310 & 0.399 & 0.506 \\
\hline SRI & 0.209 & 0.149 & 0.196 & 0.012 & 0.012 & 0.012 & 4.936 & 3.482 & 4.564 & 39.790 & 56.116 & 42.545 & 17.289 & 31.269 & 30.035 & 0.301 & 0.386 & 0.489 \\
\hline CGA & 0.186 & 0.137 & 0.179 & 0.012 & 0.012 & 0.012 & 4.394 & 3.214 & 4.203 & 44.792 & 60.897 & 46.306 & 17.365 & 31.372 & 30.138 & 0.269 & 0.357 & 0.451 \\
\hline CGB & 0.187 & 0.141 & 0.187 & 0.010 & 0.010 & 0.010 & 4.421 & 3.316 & 4.362 & 44.505 & 58.970 & 44.553 & 17.419 & 31.440 & 30.211 & 0.271 & 0.369 & 0.470 \\
\hline CGC & 0.171 & 0.131 & 0.174 & 0.008 & 0.009 & 0.009 & 4.047 & 3.085 & 4.070 & 48.679 & 63.480 & 47.837 & 17.462 & 31.498 & 30.271 & 0.249 & 0.344 & 0.439 \\
\hline Obese & 0.279 & 0.163 & 0.212 & 0.013 & 0.014 & 0.014 & 6.531 & 3.812 & 4.919 & 29.843 & 51.078 & 39.385 & 18.350 & 31.462 & 30.155 & 0.426 & 0.427 & 0.531 \\
\hline O-SRI & 0.271 & 0.156 & 0.202 & 0.012 & 0.012 & 0.012 & 6.338 & 3.646 & 4.698 & 30.778 & 53.529 & 41.280 & 18.346 & 31.452 & 30.147 & 0.413 & 0.407 & 0.506 \\
\hline O-CGC & 0.231 & 0.139 & 0.181 & 0.008 & 0.009 & 0.009 & 5.428 & 3.27 & 4.222 & 36.058 & 59.808 & 46.061 & 18.485 & 31.673 & 30.378 & 0.355 & 0.367 & 0.457 \\
\hline
\end{tabular}

MRI, moderate renal impairment; SRI, severe renal impairment; CGA, cirrhosis grade A; CGB, cirrhosis grade B; CGC, cirrhosis grade C; O-SRI, Obese with severe renal impairment; O-CGC, Obese with cirrhosis grade C.

Table 3. Simulated pharmacokinetics of remdesivir nucleoside core (GS-441524; $200 \mathrm{mg}$ intravenous) in 30 year-old (85.5 kg) healthy subject.

\begin{tabular}{|c|c|c|c|c|c|c|}
\hline & $\begin{array}{c}C_{\max } \\
(\mu \mathrm{g} / \mathrm{mL})\end{array}$ & $\begin{array}{l}C_{\text {maxLiver }} \\
(\mu \mathrm{g} / \mathrm{mL})\end{array}$ & $\begin{array}{c}\mathrm{AUC} \mathbf{C}_{\mathbf{0} \infty} \\
(\boldsymbol{\mu g}-\mathbf{h} / \mathbf{m L})\end{array}$ & $\begin{array}{c}\text { CLsys } \\
(\mathrm{L} / \mathrm{h})\end{array}$ & $\begin{array}{l}\text { VsS } \\
\text { (L) }\end{array}$ & $\begin{array}{l}T_{1 / 2} \\
(h)\end{array}$ \\
\hline Healthy & 1.54 & 0.89 & 27.873 & 5.205 & 34.59 & 4.61 \\
\hline MRI & 2.58 & 1.49 & 40.39 & 2.68 & 34.59 & 8.93 \\
\hline SRI & 3.66 & 2.13 & 51.46 & 1.36 & 34.59 & 17.58 \\
\hline CGA & 1.99 & 1.16 & 33.62 & 3.84 & 34.52 & 6.23 \\
\hline CGB & 2.24 & 1.30 & 36.55 & 3.29 & 34.47 & 7.26 \\
\hline CGC & 2.26 & 1.32 & 36.84 & 3.24 & 34.42 & 7.36 \\
\hline Obese & 1.54 & 0.89 & 28.06 & 5.24 & 33.44 & 4.43 \\
\hline O-SRI & 3.73 & 2.17 & 52.65 & 1.37 & 33.44 & 16.94 \\
\hline O-CGC & 2.27 & 1.32 & 37.35 & 3.26 & 33.28 & 7.09 \\
\hline
\end{tabular}

MRI, moderate renal impairment; SRI, severe renal impairment; CGA, cirrhosis grade A; CGB, cirrhosis grade B; CGC, cirrhosis grade C; O-SRI, Obese with severe renal impairment; O-CGC, Obese with cirrhosis grade C. 
Table 5. CYP3A4-related simulated drug-drug interactions of remdesivir with COVID-19 drug regimens and drugs for comorbidities in the steady-state prediction DDI mode.

\begin{tabular}{|c|c|c|c|c|}
\hline Victim & Perpetrator & Nature & $\begin{array}{l}\text { AUC } \\
\text { Ratio }\end{array}$ & $\begin{array}{l}\text { Perpetrator } \\
\text { Classification }\end{array}$ \\
\hline \multicolumn{5}{|c|}{ COVID-19 Regimen } \\
\hline Remdesivir & Chloroquine & Inhibitor & 1.331 & Weak \\
\hline Remdesivir & Dexamethasone & Inhibitor & 1.004 & No interaction \\
\hline Remdesivir & Dexamethasone & Induction & 0.957 & No interaction \\
\hline Remdesivir & Ritonavir & Inhibitor & 40.04 & Strong \\
\hline Remdesivir & Lopinavir & Inhibitor & 1.142 & No interaction \\
\hline Remdesivir & Azithromycin & Inhibitor & 1.015 & No interaction \\
\hline Remdesivir & Ivermectin & Inhibitor & 1.012 & No interaction \\
\hline \multicolumn{5}{|c|}{ Drugs for Comorbidities } \\
\hline Remdesivir & Carbamazepine & Induction & 0.059 & Strong \\
\hline Remdesivir & Phenytoin & Induction & 0.154 & Strong \\
\hline Remdesivir & Amiodarone & Inhibitor & 5.814 & Strong \\
\hline Remdesivir & Voriconazole & Inhibitor & 10.97 & Strong \\
\hline Remdesivir & Diltiazem & Inhibitor & 11.63 & Strong \\
\hline Remdesivir & Verapamil & Inhibitor & 14.46 & Strong \\
\hline Remdesivir & Cyclosporine & Inhibitor & 1.061 & No interaction \\
\hline Remdesivir & Nicardipine & Inhibitor & 1.156 & No interaction \\
\hline \multicolumn{5}{|c|}{$\begin{array}{l}\text { Inhibitors were classified as weak (predicted AUC ratio } 1.25 \\
\text { to 2), moderate (predicted AUC ratio } 2 \text { to } 5 \text { ) or strong } \\
\text { (predicted AUC ratio }>5 \text { ). Inducers were classified as weak } \\
\text { (predicted AUC ratio } 0.5 \text { to } 0.8 \text {; less than two-fold difference } \\
\text { from the baseline), moderate (predicted AUC ratio } 0.2 \text { to } 0.5 \text {; } \\
\text { two-to-five-fold difference from the baseline), strong } \\
\text { (predicted AUC ratio }<0.2 \text {; more than fivefold difference from } \\
\text { the baseline). }\end{array}$} \\
\hline
\end{tabular}

\section{DISCUSSION}

Remdesivir, which was originally developed against Ebola, is somewhat effective against SARS-CoV-2 due its ability to inhibit the RNA polymerase enzyme of SARS-CoV-2 $(8,16)$. The FDA approved remdesivir in adults and pediatric patients who are at least 12 years or older weighing at least $40 \mathrm{~kg}$ and require hospitalization due to COVID-19 (9). Most clinical guidelines recommend dexamethasone and remdesivir to be given in combination in patients who are on supplemental oxygen $(2,6)$. Although remdesivir is the only FDA approved agent for COVID-19, the drug does not have the detail ADME and DDI characterization data in public domain. The purpose of this study was to simulate the physicochemical, metabolic and transporter, pharmacokinetics, and DDI potential with other COVID-19 regimen drugs and agents that are concomitantly used for preexisting conditions or supportive care.

\begin{tabular}{|c|c|c|c|}
\hline \multicolumn{4}{|c|}{$\begin{array}{l}\text { Table 4. Correlation of physiological status with the } \\
\text { predicted PK parameters. }\end{array}$} \\
\hline $\begin{array}{l}\text { Physiological } \\
\text { Status }\end{array}$ & $\begin{array}{l}\text { Pharmacokinetics } \\
\text { Parameter }\end{array}$ & $\mathbf{R}^{2}$ & p-value \\
\hline \multirow[t]{6}{*}{ Age } & $\mathrm{C}_{\max }(\mu \mathrm{g} / \mathrm{mL})$ & 0.070 & 0.612 \\
\hline & $\mathrm{C}_{\text {maxLiver }}(\mu \mathrm{g} / \mathrm{mL})$ & 0.677 & 0.04 \\
\hline & $\mathrm{AUC}_{0-\infty}(\mu \mathrm{g}-\mathrm{h} / \mathrm{mL})$ & 0.081 & 0.583 \\
\hline & CLsys $(\mathrm{L} / \mathrm{h})$ & 0.049 & 0.673 \\
\hline & Vss (L) & 0.484 & 0.125 \\
\hline & $\mathrm{T}_{1 / 2}(\mathrm{~h})$ & 0.911 & 0.003 \\
\hline \multirow[t]{6}{*}{ Liver status } & $\mathrm{C}_{\max }(\mu \mathrm{g} / \mathrm{mL})$ & 0.872 & 0.06 \\
\hline & $\mathrm{C}_{\text {maxLiver }}(\mu \mathrm{g} / \mathrm{mL})$ & 0.967 & 0.016 \\
\hline & $\mathrm{AUC}_{0-\infty}(\mu \mathrm{g}-\mathrm{h} / \mathrm{mL})$ & 0.764 & 0.125 \\
\hline & CLsys (L/h) & 0.858 & 0.073 \\
\hline & Vss (L) & 0.987 & 0.006 \\
\hline & $\mathrm{T}_{1 / 2}(\mathrm{~h})$ & 0.848 & 0.079 \\
\hline \multirow[t]{6}{*}{ Renal status } & $\mathrm{C}_{\max }(\mu \mathrm{g} / \mathrm{mL})$ & 0.937 & 0.160 \\
\hline & $\mathrm{C}_{\text {maxLiver }}(\mu \mathrm{g} / \mathrm{mL})$ & 1.000 & 0.006 \\
\hline & $\mathrm{AUC}_{0-\infty}(\mu \mathrm{g}-\mathrm{h} / \mathrm{mL})$ & 0.963 & 0.121 \\
\hline & CLsys (L/h) & 0.959 & 0.129 \\
\hline & Vss (L) & 0.877 & 0.227 \\
\hline & $\mathrm{T}_{1 / 2}(\mathrm{~h})$ & 0.967 & 0.115 \\
\hline \multicolumn{4}{|c|}{$\begin{array}{l}\text { Scales of interpretation from coefficient of determination (R2) } \\
\text { values: } 0.90-1.00 \text { (strong positive correlation), 0.70-0.89 } \\
\text { (fairly strong positive correlation), 0.50-0.69 (moderate } \\
\text { positive correlation), } 0.10-0.49 \text { (weak positive correlation), } \\
0.09-0.00 \text { (no correlation). The following subtypes of groups } \\
\text { were used to carry out the correlation study. Ages: } 10,12,18 \text {, } \\
30,50,75 \text { year; Liver status: healthy, cirrhosis grade A, } \\
\text { cirrhosis grade B, cirrhosis grade C; Renal status: healthy, } \\
\text { moderate renal impairment, severe renal impairment. A p } \\
\text { value <0.05 indicates statistical significance. }\end{array}$} \\
\hline
\end{tabular}

The physicochemical, metabolism and transporter properties of remdesivir were determined by ADMET Predictor module of GastroPlus software. Remdesivir prodrug, GS-5734, was more lipophilic than its nucleoside core, GS-441524. Similarly, the nucleoside core is predicted to be $>100$-fold more water soluble that the parent drug. Remdesivir was designed as a prodrug to improve its bioavailability and deeper tissue penetration. Interestingly, the nucleoside core had a higher predicted blood brain penetration than the prodrug. GastroPlus ADMET Predictor features can predict the involvement of CYP enzymes and transporters. Simulation data suggest that remdesivir prodrug, GS5734, but not the nucleoside core, can undergo CYPmeditated metabolism in humans. CYP enzymes, 
specifically, CYP3A4, metabolizes xenobiotic substances and their functions can also be modified by different drugs, natural products, and dietary substances (13). Remdesivir prodrug and nucleoside core were substrates for both OATP1B3 and P-gp. In addition, BCRP contributes to the transport of remdesivir, whereas OCT1 and OAT3 do the same for nucleoside. Similarly, Sato et al. (2021) has reported that OATP4C1, the sole transporter from OATP family in kidney, acts as an uptake transporter of remdesivir in human renal proximal tubular cell and can have potential effect on remdesivir disposition (39).

The pharmacokinetic profile of both GS-5734 and GS-441524 in a 30-year-old healthy virtual volunteer varied in different parameters. The $\mathrm{C}_{\max }$ in plasma, $\mathrm{C}_{\max }$ in the liver, $\mathrm{AUC}_{0-\infty}$, Vss, and $\mathrm{T}_{1 / 2}$ for GS-441524 were higher than GS-5734. The systemic clearance of GS-5734 was greater than GS-441524 which suggests that GS-5734 is systemically cleared faster from the body than GS-441524. This could be due to the fact that GS-5734 is predicted to be metabolized by CYP3A4, as opposed to GS-441524 that was predicted to have no CYP involvement in its metabolism. Systemic clearance is the summation of various tissue clearance mechanisms which include renal, hepatic, and biliary (14). The elevated clearance may explain why the maximum plasma concentration in GS-5734 is lower than GS-441524. The renal or hepatic clearances also showed significant effect on PK parameters. Patients who had mild or severe renal or hepatic impairment demonstrated a strong positive correlation with all the PK parameters studied in the present work. Though very limited PK data are available for remdesivir, select PK properties of remdesivir and nucleoside core (GS-441524) have been reported either in a single (age mid-seventies), two (66- and 67-year-old) or nine (mean age 56 years) ICU patients with severe COVID-19 infection (17, 19, 40). Humeniuk et al. (2020) reported remdesivir and GS-441524 PK profile in healthy individuals with mean age of the subjects in their forties (18). Our simulated results mimicked the reported parameters in these brief studies. For example, Tempestilli et al. (2020) reported a range of remdesivir AUC between $2.9 \mu \mathrm{g}-\mathrm{h} / \mathrm{mL}$ to $4.0 \mu \mathrm{g}-\mathrm{h} / \mathrm{mL}$ which encompasses the values obtained in our simulation for different age groups (19). Similarly, the $C_{\max }(1.15 \mu \mathrm{g} / \mathrm{mL})$ and AUC $(18.4 \mu \mathrm{g}-\mathrm{h} / \mathrm{mL})$ values of GS-441524 in the Sorgel et al. (2020) single patient study is comparable to the values in our analyses (40). Overall, the simulation results obtained from our study are comparable with the sparse PK studies reported with very limited sample size. Also, it is worthwhile to recognize that our study highlighted PK profile in a wide range of age groups with diverse physiological conditions that capture the general population infected with SARS-CoV-2.

The pharmacokinetic profile of GS-5734 was simulated in various PBPK models of age groups ranging from 12 to 75 years. When comparing healthy virtual volunteers, the $\mathrm{C}_{\max }$ and $\mathrm{AUC}_{0-\infty}$ parameters demonstrated U-shape profiles with comparable values among pediatric and geriatric populations. The similarity in the lower expression and function of metabolic enzymes in the early and later stages of human life is likely one of the contributing factors to the $\mathrm{U}$-shape profile of $\mathrm{C}_{\max }$ and $\mathrm{AUC}_{0-\infty}$ parameters $(12,41)$. It is important to recognize that in general both $\mathrm{C}_{\max }$ and $\mathrm{AUC}_{0-\infty}$ are heavily affected by the status of drug metabolizing enzymes such as CYPs $(12,41)$. The geriatric population in turn showed noticeable difference in CLsys, Vss, and $\mathrm{T}_{1 / 2}$; but only a mild difference in the $\mathrm{C}_{\text {maxLiver }}$. The most distinguishable difference was observed in Vss with 17.295 L and $30.043 \mathrm{~L}$ in 12year and 75-year-old groups. Factors that can influence these predicted results include polypharmacy, water composition, protein binding, body weight ratios, metabolic enzyme status, and renal function (41). The Vss differences significantly due to adults being composed of more fat than children offering more tissue dispersion than children (41). Children are more composed of water than adults which could affect volume of distribution and the drug levels (41). In addition to the age, other physiological and pathological factors such as weight, liver and renal function status correlated with major PK parameters. This indicated that remdesivir PK profile could be variable depending on the status of the COVID-19 patients. Several clinical studies have suggested that liver and renal functions are potential compromised during the severe COVID-19 which can alter remdesivir PK $(1,40,42)$.

The DDIs of remdesivir with COVID-19 treatment regimens and drugs commonly used for chronic conditions (e.g., heart disease, seizures) were simulated. Since remdesivir is predicted to be a substrate of CYP3A4, medications that can interfere with CYP functions have the potential to alter remdesivir disposition. The perpetrator drugs can alter the concentration of the remdesivir, the victim drug, either through inhibition or induction. Ritonavir, which is given with lopinavir in COVID19 treatment, was the only drug to have a perpetrator 
classification as strong for interaction with remdesivir. Chloroquine was the only other COVID19 regimen drug analyzed in the present study to have a weak inhibitory effect. Among the drugs for comorbidities, CYP3A4 inducers or inhibitors demonstrated DDI potential. Amiodarone, voriconazole, diltiazem, and verapamil appear to be strong perpetrators in remdesivir DDI. The inhibition of remdesivir metabolism could lead to increased toxic plasma concentrations. Indeed, remdesivir has been linked to nephrotoxicity, cardiovascular toxicity, and hepatotoxicity in COVID-19 patients (43). It has shown to increase liver enzymes such as aspartate transaminase and alanine transaminase and cause liver injury in COVID-19 patients $(43,44)$. It is potential that some of the remdesivir-related toxicity is an outcome of DDIs with the COVID-19 treatment regimens and/or with the drugs for comorbidities. Remdesivir when administered with amiodarone caused liver toxicity in COVID-19 patients (42). On the contrary, carbamazepine and phenytoin are the two agents that are predicted to increase remdesivir metabolism, leading to plausible subtherapeutic concentrations and poor antiviral activity. A limitation of the present study relates to GastroPlus software which is designed to identify DDIs involving CYPs but not non-CYP enzymes. Thus, polypharmacy to manage an array of COVID19 symptoms and preexisting conditions can facilitate significant toxicity or therapeutic failure in patients.

\section{CONCLUSION}

In conclusion, there is limited experimental biopharmaceutical properties available for remdesivir at this time. The objective of our study was to simulate and predict the physicochemical, pharmacokinetic, and potential DDIs associated with remdesivir, and characterize remdesivir PK properties in special populations which are highly affected by COVID-19. GS-5734 was more lipophilic than GS-441524. The remdesivir prodrug, GS-5734, but not the nucleoside core, is predicted to be a CYP3A4 substrate. The pharmacokinetic parameters were predicted in PBPK simulated models with different age, weight, liver and renal function status which reflected the special population patient group. Correlations studies were conducted to measure the relationship between physiological and pathological factors with pharmacokinetic parameters. The majority of the correlations were classified as having a strong positive correlation.
DDI simulations were conducted with remdesivir, COVID-19 regimens, and drugs used in comorbidities. Ritonavir, chloroquine, amiodarone, voriconazole, diltiazem, and verapamil were associated with CYP-mediated inhibition of remdesivir metabolism. Carbamazepine and phenytoin were associated with CYP-mediated induction of remdesivir metabolism. These perpetrator drugs are predicted to alter remdesivir concentrations to either supratherapeutic or subtherapeutic concentrations. Overall, understanding the predicted ADME, PK, and DDI properties of remdesivir will afford better treatment outcomes in COVID-19 patients.

ACKNOWLEDGEMENT. The GastroPlus software 9.8 version was provided to S.D. by Simulations Plus, Inc. (Lancaster, CA) as an in-kind research support.

\section{CONFLICTS OF INTEREST. None.}

\section{REFERENCES}

1. Deb S, Arrighi S. Potential Effects of COVID-19 on Cytochrome P450-Mediated Drug Metabolism and Disposition in Infected Patients. Eur J Drug Metab Pharmacokinet. 2021;46(2):185-203. doi:10.1007/s13318-020-00668-8

2. Infectious Diseases Society of America. COVID19 Guideline, Part 1: Treatment and Management. IDSA Home. Availabe online: https://www.idsociety.org/practiceguideline/covid-19-guideline-treatment-andmanagement/. Accessed on March 28, 2021.

3. Khuroo MS. Chloroquine and hydroxychloroquine in coronavirus disease 2019 (COVID-19). Facts, fiction and the hype: a critical appraisal. Int $\mathbf{J}$ Antimicrob Agents. 2020;56(3):106101. doi:10.1016/j.ijantimicag.2020.106101

4. Kaur H, Shekhar N, Sharma S, Sarma P, Prakash A, Medhi B. Ivermectin as a potential drug for treatment of COVID-19: an in-sync review with clinical and computational attributes. Pharmacol Rep. 2021. doi:10.1007/s43440-020-00195-y

5. Meini S, Pagotto A, Longo B, Vendramin I, Pecori D, Tascini C. Role of Lopinavir/Ritonavir in the Treatment of Covid-19: A Review of Current Evidence, Guideline Recommendations, and Perspectives. J Clin Med. 2020;9(7). doi: $10.3390 /$ jcm9072050

6. Siemieniuk R, Rochwerg B, Agoritsas T, et al. A living WHO guideline on drugs for covid-19. BMJ. 2020;370:m3379. doi:10.1136/bmj.m3379 
7. U.S. Food and Drug Administration. Coronavirus (COVID-19) Update: FDA Issues Emergency Use Authorization for Potential COVID-19 Treatment. Availabe online: https://www.fda.gov/newsevents/press-announcements/coronavirus-covid19-update-fda-issues-emergency-useauthorization-potential-covid-19-

treatment\#: :text=The\%20emergency\%20use $\% 20$ authorization $\% 20$ allows, children $\% 20$ hospitalized $\% 20$ with\%20severe\%20disease. Accessed on March 28, 2021.

8. Eastman RT, Roth JS, Brimacombe KR, et al. Remdesivir: A Review of Its Discovery and Development Leading to Emergency Use Authorization for Treatment of COVID-19. ACS Cent Sci. 2020;6(5):672-83. doi:10.1021/acscentsci.0c00489

9. VEKLURY® (remdesivir) Package Insert. 2020; https://www.vekluryhcp.com/. Accessed March 28, 2021.

10. Beigel JH, Tomashek KM, Dodd LE, et al. Remdesivir for the Treatment of Covid-19 - Final Report. N Engl J Med. 2020;383(19):1813-26. doi:10.1056/NEJMoa2007764

11. Chiotos K, Hayes M, Kimberlin DW, et al. Multicenter Interim Guidance on Use of Antivirals for Children With Coronavirus Disease 2019/Severe Acute Respiratory Syndrome Coronavirus 2. J Pediatric Infect Dis Soc. 2021;10(1):34-48. doi:10.1093/jpids/piaa115

12. Gad SC. Preclinical Development Handbook: ADME and Biopharmaceutical Properties:: Wiley; 2008 (ISBN: 978-0-470-24847-8).

13. Deb S, Pandey M, Adomat H, Guns ES. Cytochrome P450 3A-mediated microsomal biotransformation of 1alpha,25-dihydroxyvitamin D3 in mouse and human liver: drug-related induction and inhibition of catabolism. Drug Metab Dispos. 2012;40(5):907-18. doi:10.1124/dmd.111.041681

14. Deb S, Reeves AA, Lafortune S. Simulation of Physicochemical and Pharmacokinetic Properties of Vitamin D3 and Its Natural Derivatives. Pharmaceuticals (Basel). 2020;13(8). doi:10.3390/ph13080160

15. Dodd S, Kollipara S, Sanchez-Felix M, et al. Prediction of ARA/PPI Drug-Drug Interactions at the Drug Discovery and Development Interface. J Pharm Sci. 2019;108(1):87-101. doi:10.1016/j.xphs.2018.10.032

16. Gholamhoseini MT, Yazdi-Feyzabadi V, Goudarzi R, Mehrolhassani MH. Safety and Efficacy of Remdesivir for the Treatment of COVID-19: A Systematic Review and Meta-Analysis J Pharm Pharm Sci. 2021;24:237-45.

17. Corcione S, De Nicolo A, Montrucchio G, et al. Real life Study on the Pharmacokinetic of Remdesivir in ICU patients admitted for Severe
COVID-19 Pneumonia. Br J Clin Pharmacol. 2021. doi:10.1111/bcp.14895

18. Humeniuk R, Mathias A, Cao H, et al. Safety, Tolerability, and Pharmacokinetics of Remdesivir, An Antiviral for Treatment of COVID-19, in Healthy Subjects. Clin Transl Sci. 2020;13(5):896906. doi:10.1111/cts. 12840

19. Tempestilli M, Caputi P, Avataneo V, et al. Pharmacokinetics of remdesivir and GS-441524 in two critically ill patients who recovered from COVID-19. J Antimicrob Chemother. 2020;75(10):2977-80. doi:10.1093/jac/dkaa239

20. National Center for Biotechnology Information. PubChem. 2021. https://pubchem.ncbi.nlm.nih.gov/ Accessed March 28, 2021

21. Centers for Disease Control and Prevention (CDC). About Adult BMI. https://www.cdc.gov/healthyweight/assessing/bmi /adult_bmi/index.html. Accessed March 28, 2021

22. Durand F, Valla D. Assessment of the prognosis of cirrhosis: Child-Pugh versus MELD. J Hepatol. 2005;42 doi:10.1016/j.jhep.2004.11.015

23. Amundsen R, Asberg A, Ohm IK, Christensen H. Cyclosporine A- and tacrolimus-mediated inhibition of CYP3A4 and CYP3A5 in vitro. Drug Metab Dispos. 2012;40(4):655-61. doi:10.1124/dmd.111.043018

24. Barve A, Kovacs SJ, Ke J, et al. The effects of CYP3A4 induction and inhibition on the pharmacokinetics of alisporivir in humans. Clin Pharmacol Drug Dev. 2015;4(1):25-32. doi:10.1002/cpdd.114

25. Burt HJ, Galetin A, Houston JB. IC50-based approaches as an alternative method for assessment of time-dependent inhibition of CYP3A4. Xenobiotica. doi:10.3109/00498251003698555

26. Jeong S, Nguyen PD, Desta Z. Comprehensive in vitro analysis of voriconazole inhibition of eight cytochrome P450 (CYP) enzymes: major effect on CYPs 2B6, 2C9, 2C19, and 3A. Antimicrob Agents Chemother. 2009;53(2):541-51. doi:10.1128/AAC.01123-08

27. Li X, Hohl R, Sorgel F, Fuhr U. The parent drugs chloroquine and hydroxychloroquine do not inhibit human CYP3A activity in vitro. Eur $\mathbf{J}$ Clin Pharmacol. 2020;76(10):1481-2. doi:10.1007/s00228-020-02928-7

28. McGinnity DF, Zhang G, Kenny JR, et al. Evaluation of multiple in vitro systems for assessment of CYP3A4 induction in drug discovery: human hepatocytes, pregnane $\mathrm{X}$ receptor reporter gene, and $\mathrm{Fa} 2 \mathrm{~N}-4$ and HepaRG cells. Drug Metab Dispos. 2009;37(6):1259-68. doi:10.1124/dmd.109.026526 
29. Nakamura K, Ariyoshi N, Iwatsubo T, et al. Inhibitory effects of nicardipine to cytochrome P450 (CYP) in human liver microsomes. Biol Pharm Bull. 2005;28(5):882-5. doi:10.1248/bpb.28.882

30. Ohyama K, Nakajima M, Suzuki M, Shimada N, Yamazaki H, Yokoi T. Inhibitory effects of amiodarone and its $\mathrm{N}$-deethylated metabolite on human cytochrome $\mathrm{P} 450$ activities: prediction of in vivo drug interactions. $\mathrm{Br} \mathrm{J}$ Clin Pharmacol. 2000;49(3):244-53. doi:10.1046/j.13652125.2000.00134.x

31. Pichard L, Fabre I, Daujat M, Domergue J, Joyeux $\mathrm{H}$, Maurel P. Effect of corticosteroids on the expression of cytochromes $\mathrm{P} 450$ and on cyclosporin A oxidase activity in primary cultures of human hepatocytes. Mol Pharmacol. 1992;41(6):1047-55.

32. Rowland Yeo K, Walsky RL, Jamei M, RostamiHodjegan A, Tucker GT. Prediction of timedependent CYP3A4 drug-drug interactions by physiologically based pharmacokinetic modelling: impact of inactivation parameters and enzyme turnover. Eur J Pharm Sci. 2011;43(3):160-73. doi:10.1016/j.ejps.2011.04.008

33. Vermet H, Raoust N, Ngo R, et al. Evaluation of Normalization Methods To Predict CYP3A4 Induction in Six Fully Characterized Cryopreserved Human Hepatocyte Preparations and HepaRG Cells. Drug Metab Dispos. 2016;44(1):50-60. doi:10.1124/dmd.115.065581

34. Weemhoff JL, von Moltke LL, Richert C, Hesse LM, Harmatz JS, Greenblatt DJ. Apparent mechanism-based inhibition of human CYP3A invitro by lopinavir. J Pharm Pharmacol. 2003;55(3):381-6. doi:10.1211/002235702739

35. Yeo KR, Yeo WW. Inhibitory effects of verapamil and diltiazem on simvastatin metabolism in human liver microsomes. $\mathrm{Br} \mathrm{J}$ Clin Pharmacol. 2001;51(5):461-70. doi:10.1046/j.13652125.2001.01386.x

36. Kumar GN, Dykstra J, Roberts EM, et al. Potent inhibition of the cytochrome P-450 3A-mediated human liver microsomal metabolism of a novel HIV protease inhibitor by ritonavir: A positive drug-drug interaction. Drug Metab Dispos. 1999;27(8):902-8.

37. U.S. Food and Drug Administration. Clinical Drug Interaction Studies- Cytochrome P450 Enzymeand Transporter-Mediated Drug Interactions Guidance for Industry. 2021 https://www.fda.gov/media/134581/download. Accessed March 28, 2021

38. Fraczkiewicz R, Lobell M, Goller AH, et al. Best of both worlds: combining pharma data and state of the art modeling technology to improve in Silico pKa prediction. J Chem Inf Model. 2015;55(2):389-97. doi:10.1021/ci500585w
39. Sato T, Maekawa M, Mano N, Abe T, Yamaguchi H. Role of OATP4C1 in Renal Handling of Remdesivir and its Nucleoside Analog GS-441524: The First Approved Drug for Patients with COVID-19 J Pharm Pharm Sci. 2021;24:227-236. doi:https://doi.org/10.18433/jpps31813

40. Sorgel F, Malin JJ, Hagmann $\mathrm{H}$, et al. Pharmacokinetics of remdesivir in a COVID-19 patient with end-stage renal disease on intermittent haemodialysis. J Antimicrob Chemother. 2021;76(3):825-7. doi:10.1093/jac/dkaa500

41. Stephenson T. How children's responses to drugs differ from adults. $\mathrm{Br} \mathrm{J}$ Clin Pharmacol. 2005;59(6):670-3. doi:10.1111/j.13652125.2005.02445.x

42. Leegwater E, Strik A, Wilms EB, et al. Druginduced liver injury in a COVID-19 patient: potential interaction of remdesivir with $\mathrm{P}$ glycoprotein inhibitors. Clin Infect Dis. 2020. doi:10.1093/cid/ciaa883

43. Fan Q, Zhang B, Ma J, Zhang S. Safety profile of the antiviral drug remdesivir: An update. Biomed Pharmacother. 2020;130:110532. doi:10.1016/j.biopha.2020.110532

44. Zampino R, Mele F, Florio LL, et al. Liver injury in remdesivir-treated COVID-19 patients. Hepatol Int. 2020;14(5):881-3. doi:10.1007/s12072-02010077-3 


\section{SUPPLEMENTARY DATA. Simulation of Remdesivir Disposition and Its Drug Interactions}

Table S1: Characteristics of different populations used in the simulation study.

\begin{tabular}{|c|c|c|c|c|c|c|}
\hline & 10 yo & 12 yo & 18 yo & 30 yo & 50 yo & 75 yo \\
\hline Healthy & $38.9 \mathrm{~kg}$ & $48.58 \mathrm{~kg}$ & $76.2 \mathrm{~kg}$ & $85.5 \mathrm{~kg}$ & $89.02 \mathrm{~kg}$ & $82.16 \mathrm{~kg}$ \\
\hline MRI & $38.9 \mathrm{~kg}$ & $48.58 \mathrm{~kg}$ & $76.2 \mathrm{~kg}$ & $85.5 \mathrm{~kg}$ & $89.02 \mathrm{~kg}$ & $82.16 \mathrm{~kg}$ \\
\hline SRI & $38.9 \mathrm{~kg}$, & $48.58 \mathrm{~kg}$ & $76.2 \mathrm{~kg}$ & $85.5 \mathrm{~kg}$ & $89.02 \mathrm{~kg}$ & $82.16 \mathrm{~kg}$ \\
\hline CGA & $38.9 \mathrm{~kg}$, & $48.58 \mathrm{~kg}$ & $76.2 \mathrm{~kg}$ & $85.5 \mathrm{~kg}$ & $89.02 \mathrm{~kg}$ & $82.16 \mathrm{~kg}$ \\
\hline CGB & $38.9 \mathrm{~kg}$, & $48.58 \mathrm{~kg}$ & $76.2 \mathrm{~kg}$ & $85.5 \mathrm{~kg}$ & $89.02 \mathrm{~kg}$ & $82.16 \mathrm{~kg}$ \\
\hline CGC & $38.9 \mathrm{~kg}$ & $48.58 \mathrm{~kg}$ & $76.2 \mathrm{~kg}$ & $85.5 \mathrm{~kg}$ & $89.02 \mathrm{~kg}$ & $82.16 \mathrm{~kg}$ \\
\hline Obese & $\begin{array}{l}38.9 \mathrm{~kg} \text {, height } 130 \\
\mathrm{~cm}, \text { Obese (BMI 23) }\end{array}$ & $\begin{array}{l}48.58 \mathrm{~kg} \text {, height } 127 \\
\mathrm{~cm}, \text { Obese (BMI 23) }\end{array}$ & $\begin{array}{l}76.2 \mathrm{~kg} \text {, height } 159.38 \\
\mathrm{~cm}, \text { Obese (BMI 30) }\end{array}$ & $\begin{array}{l}85.5 \mathrm{~kg} \text {, height } 166.1 \mathrm{~cm} \\
\text { Obese (BMI 31) }\end{array}$ & $\begin{array}{l}89.02 \mathrm{~kg} \text {, height } 172.26 \mathrm{~cm} \text {, } \\
\text { Obese (BMI 30) }\end{array}$ & $\begin{array}{l}82.16 \mathrm{~kg} \text {, height } 165.49 \\
\mathrm{~cm} \text {, Obese (BMI 30) }\end{array}$ \\
\hline O-SRI & $\begin{array}{l}38.9 \mathrm{~kg} \text {, height } 130 \\
\mathrm{~cm}, \text { Obese (BMI 23) }\end{array}$ & $\begin{array}{l}48.58 \mathrm{~kg}, \text { height } 127 \\
\mathrm{~cm}, \text { Obese (BMI 30) }\end{array}$ & $\begin{array}{l}76.2 \mathrm{~kg} \text {, height } 159.38 \\
\mathrm{~cm}, \text { Obese (BMI 30) }\end{array}$ & $\begin{array}{l}85.5 \mathrm{~kg} \text {, height } 166.1 \mathrm{~cm} \\
\text { Obese (BMI 31) }\end{array}$ & $\begin{array}{l}89.02 \mathrm{~kg} \text {, height } 172.26 \mathrm{~cm} \text {, } \\
\text { Obese (BMI 30) }\end{array}$ & $\begin{array}{l}82.16 \mathrm{~kg} \text {, height } 165.49 \\
\mathrm{~cm} \text {, Obese (BMI 30) }\end{array}$ \\
\hline O-CGC & $\begin{array}{l}38.9 \mathrm{~kg} \text {, height } 130 \\
\mathrm{~cm}, \text { Obese (BMI 23), }\end{array}$ & $\begin{array}{l}38.9 \mathrm{~kg} \text {, height } 130 \mathrm{~cm} \text {, } \\
\text { Obese (BMI 23) }\end{array}$ & $\begin{array}{l}76.2 \mathrm{~kg} \text {, height } 159.38 \\
\mathrm{~cm}, \text { Obese (BMI 30) }\end{array}$ & $\begin{array}{l}85.5 \mathrm{~kg} \text {, height } 166.1 \mathrm{~cm} \\
\text { Obese (BMI 31) }\end{array}$ & $\begin{array}{l}89.02 \mathrm{~kg} \text {, height } 172.26 \mathrm{~cm} \text {, } \\
\text { Obese (BMI 30) }\end{array}$ & $\begin{array}{l}82.16 \mathrm{~kg} \text {, height } 165.49 \\
\mathrm{~cm}, \text { Obese (BMI 30) }\end{array}$ \\
\hline
\end{tabular}

yo, year old; MRI, moderate renal impairment; SRI, severe renal impairment; CGA, cirrhosis grade A; CGB, cirrhosis grade B; CGC, cirrhosis grade C; O-SRI, Obese with severe renal impairment; O-CGC, Obese with cirrhosis grade C.

Table S2: Remdesivir (200 mg intravenous) pharmacokinetics in 10, 18 and 50 year old virtual subjects.

\begin{tabular}{|c|c|c|c|c|c|c|c|c|c|c|c|c|c|c|c|c|c|c|}
\hline & \multicolumn{3}{|c|}{$C_{\max }(\mu \mathrm{g} / \mathrm{mL})$} & \multicolumn{3}{|c|}{$\mathrm{C}_{\text {maxLiver }}(\mu \mathrm{g} / \mathrm{mL})$} & \multicolumn{3}{|c|}{$\operatorname{AUC}_{0-\infty}(\mu \mathrm{g}-\mathrm{h} / \mathrm{mL})$} & \multicolumn{3}{|c|}{ CLsys (L/h) } & \multicolumn{3}{|c|}{ Vss (L) } & \multicolumn{3}{|c|}{$\mathbf{T}_{1 / 2}(\mathbf{h})$} \\
\hline & $10 \mathrm{Y}$ & $18 \mathrm{Y}$ & $50 \mathrm{Y}$ & $10 \mathrm{Y}$ & $18 \mathrm{Y}$ & $50 \mathrm{Y}$ & $10 \mathrm{Y}$ & $18 \mathrm{Y}$ & $50 \mathrm{Y}$ & $10 \mathrm{Y}$ & $18 \mathrm{Y}$ & $50 \mathrm{Y}$ & $10 \mathrm{Y}$ & $18 \mathrm{Y}$ & $50 \mathrm{Y}$ & $10 \mathrm{Y}$ & $18 \mathrm{Y}$ & $50 \mathrm{Y}$ \\
\hline Healthy & 0.245 & 0.165 & 0.160 & 0.013 & 0.013 & 0.014 & 5.788 & 3.868 & 3.752 & 33.030 & 50.554 & 51.934 & 13.824 & 27.680 & 32.583 & 0.290 & 0.379 & 0.435 \\
\hline MRI & 254 & 0.162 & 0.158 & 012 & 0.013 & 0.013 & 748 & 3.809 & 3.689 & 33.258 & 51.345 & 52.846 & 13.824 & 27.671 & 32.573 & 0.288 & 0.373 & 0.427 \\
\hline SRI & 0.237 & 0.157 & 0.152 & 0.011 & 0.012 & 0.012 & 5.587 & 3.688 & 3.569 & 34.231 & 53.065 & 54.665 & 13.824 & 27.670 & 32.572 & 0.280 & 0.361 & 0.413 \\
\hline CGA & 0.208 & 0.144 & 0.141 & 0.011 & 0.012 & 0.012 & 4.926 & 3.376 & 3.306 & 38.900 & 58.065 & 59.109 & 13.889 & 27.767 & 32.677 & 0.247 & 0.331 & 0.383 \\
\hline CGB & .209 & 0.147 & 0.146 & 0.009 & 0.010 & 0.010 & 4.938 & 3.459 & 3.426 & 38.797 & 56.624 & 56.974 & 13.936 & 27.831 & 32.747 & 0.249 & 0.341 & 0.398 \\
\hline CGC & 90 & 36 & 0.136 & & & & 4.509 & 3.205 & 3.196 & 42.545 & & & 13.975 & 27.886 & 32.807 & 0.228 & 0.316 & 0.372 \\
\hline Obese & 0.272 & 0.179 & 0.163 & 0.013 & 0.014 & 0.014 & 6.389 & 4.201 & 3.803 & 29.849 & 46.432 & 51.202 & 14.078 & 28.015 & 32.643 & 0.327 & 0.418 & 0.442 \\
\hline O-SRI & 0.263 & 0.172 & 0.155 & 0.011 & 0.012 & 0.012 & 6.189 & 4.024 & 3.62 & 30.829 & 48.520 & 53.869 & 14.074 & 28.007 & 32.632 & 0.316 & 0.400 & 0.420 \\
\hline O-CGC & 0.220 & 0.149 & 0.139 & 0.008 & 0.009 & 0.009 & 5.197 & 3.521 & 3.257 & 36.819 & 55.601 & 60.005 & 14.227 & 28.211 & 32.865 & 0.268 & 0.352 & 0.380 \\
\hline
\end{tabular}

MRI, moderate renal impairment; SRI, severe renal impairment; CGA, cirrhosis grade A; CGB, cirrhosis grade B; CGC, cirrhosis grade C; O-SRI, Obese with severe renal impairment; O-CGC, Obese with cirrhosis grade C. 
Table S3: Pharmacokinetics of $100 \mathrm{mg}$ intravenous remdesivir (GS-5734) in 30 year-old (85.5 kg).

\begin{tabular}{|l|c|c|c|c|c|c|}
\hline & $\mathbf{C}_{\max }(\boldsymbol{\mu g} / \mathbf{m L})$ & $\mathbf{C}_{\mathbf{m a x L i v e r}}(\boldsymbol{\mu \mathbf { g }} / \mathbf{m L})$ & $\mathbf{A U C}_{\mathbf{0}-\infty}(\boldsymbol{\mu g} \mathbf{- h} / \mathbf{m L})$ & $\left.\mathbf{C L s y s}_{\mathbf{L}} / \mathbf{h}\right)$ & $\mathbf{V s s}_{(\mathbf{L})}$ & $\mathbf{T}_{\mathbf{1} / \mathbf{2}}(\mathbf{h})$ \\
\hline Healthy & 0.078 & 0.006 & 1.829 & 53.363 & 31.281 & 0.406 \\
\hline MRI & 0.076 & 0.006 & 1.799 & 54.273 & 31.271 & 0.399 \\
\hline SRI & 0.074 & 0.006 & 1.741 & 56.116 & 31.269 & 0.386 \\
\hline CGA & 0.068 & 0.006 & 1.61 & 60.897 & 31.372 & 0.357 \\
\hline CGB & 0.071 & 0.005 & 1.658 & 58.970 & 31.440 & 0.369 \\
\hline CGC & 0.066 & 0.004 & 1.543 & 63.480 & 31.498 & 0.344 \\
\hline Obese & 0.082 & 0.007 & 1.908 & 51.078 & 31.462 & 0.427 \\
\hline O-SRI & 0.078 & 0.006 & 1.823 & 53.529 & 31.452 & 0.407 \\
\hline O-CGC & 0.069 & 0.005 & 1.635 & 59.808 & 31.673 & 0.367 \\
\hline
\end{tabular}

